\title{
Effect of Organizational Justice and Organizational Environment on Turn-Over Intention of Health Workers in Ekiti State, Nigeria
}

\author{
Ademola B. Owolabi \\ Department of Psychology \\ University of Ado-Ekiti, Nigeria \\ Tel: +234-806-670-8016_E-mail: labdem2005@yahoo.ca
}

Received: October 16, 2011

Accepted: January 25, 2012 Published: March 15, 2012

doi:10.5430/rwe.v3n1p28

URL: http://dx.doi.org/10.5430/rwe.v3n1p28

\begin{abstract}
This study investigated the effect of organizational justice and organizational environment on turn-over intention of health workers in Ekiti State, Nigeria. A total of two hundred respondents were used for the study. It comprises one hundred and two females and ninety-eight males. These respondents were drawn from three health organizations in in ekiti state. Organizational justice was measured using Organizational Justice Scale developed by Niehoff and Moornan (1993), organizational environment was measured by using Basic Psychological Needs Scale (BPNS) developed by Deci and Ryon (2000) while turnover intention was measure using Turnover Intention Scale developed by Fichman, Jenkins and Klesh (1979). The results revealed that organizational justice has a significant effect on turnover intention while organizational environment has no significant effect on turnover intention. There were no sex differences in justice perception, organizational environment and turn-over intention but there was a significant differences in justice perception and turn-over intention among the various categories of health workers.
\end{abstract}

Keywords: Organizational Justice, Turnover Intention, Organizational Environment, Health Workers, Hospitality Industry, Employees, Behavior, Justice Perception.

\section{Introduction}

The survival of any organization depends largely on the individuals working within the organization. The feeling, thinking, attitude and behavior of these employees have a far reaching effect on whether the organization will achieve its goals and objectives. The feelings of the employees and their perception of the organization determines whether they will continue to work for the organization or not. As essential as the technical competence of employees is, it is not a sufficient condition for the success of an organization. A study of organization shows that recruitment and benefits help attracts candidates to an organization while positive organizational culture and environment are the main drivers for employee satisfaction and retention. People are social beings and organizations therefore have to create settings in which employees are able to interact socially. One concept that is fundamental to human social interaction is justice. Whether, it is a promotion decision, the assignment of tasks, the allocation of rewards or just about any other type of social exchange, matters of fairness are bond to arise. Employee's perception of fairness in organization settings also known as organization justice, influence their attitude and behavior consequently, their intention to stay or quit. Turn-over is critical and costly (Bonn and Forbriger, 1992). For example, Hogan (1992) estimated that each incident of turn-over in the hospitality industry is estimated to cost up to $\$ 2,500$ in direct cost and $\$ 1600$ in indirect cost. Therefore it is highly important for management to create favorable environments that help to retain good employees.

Organizational justice as a term was coined by Greenberg (1987) and is defined as an individual's perception of and reactions to fairness in an organization. Organizational justice refers to the idea that an action or decision is morally right, which may be defined according to ethics, religion, fairness, equity, or law. People are naturally attentive to the justice of events and situations in their everyday lives, across a variety of contexts (Gopanzano, 2009). Individuals react to actions and decisions made by organizations every day. An individual's perceptions of these decisions as fair or unfair can influence the individual's subsequent attitudes and behaviors. Fairness is often of central interest to organizations because the implications of perceptions of injustice can impact job attitudes and behaviors at work. Justice in organizations can include issues related to perceptions of fair pay, equal opportunities for promotion, and personnel selection procedures. 
Greenberg (1996) categorized various conceptualization of organizational justice around a taxonomy namely; a reactive-proactive dimension and a process-content dimension. The reactive-proactive dimension focuses on employee's attempts to avoid or escape from a situation that is perceived as unfair. Some of the actions may be to force management to treat employees equally or to engage in behavior that could compensate the employee's mental distortion of unequal treatment of finally leaving the organization. On the other hand, process-content dimension focuses on the process through which decisions that are regarded as unfair by employee's are arrived at.

The justice motive theory by Lerner (1980) believes that justice is the pre-eminent concern of human being and that people allocate resources according to circumstances. According to this theory there are four factors usually considered by people why taking decision about fairness which include, competition, parity, and equity and Marxian justice.

According to Sheppard, Lewick and Minton (1992), judging the justice of a decision, action or procedure requires evaluating it against two principles namely; balance which comes to play when a person compares the reward he or she receives with that received by someone else while comparing the value of their input and correctness which refers to the rightness of the decision and encompasses elements of consistency, accuracy, clarity and procedural thoroughness. As long as procedures are clear and consistently applied, employees will perceive them to be fair. It is not only the outcome of a decision that is important to employee, the process of arriving at such decision is also very important. Intention to leave organization is one of the major responses available to employee who feels he/she has been unjustly treated by the organization.

Employees' perceptions of injustice within the organization can result in a myriad of outcomes both positive and negative. Outcomes are affected by perceptions of organizational justice as a whole or by different factors of organizational justice. Commonly cited outcomes affected by organizational justice include trust, performance, job satisfaction, organizational commitment, organizational citizenship behaviors (OCBs), counterproductive work behaviors (CWBs) absenteeism, turnover, and emotional exhaustion.

Unleashing the power of human potential in the work place through the creation of an involving and motivating organizational environment has been described as a key source of competitive advantage for business organization (Lawler 1992). A stream of literature has argued that when employees perceived the potential for satisfying their psychological needs in the work place, they engage time and effort in the organizational work.

Organizational environment is a major factor that needed to be considered in every organization. Environment is that which surrounds an individual. Our environment could either influence us positively by meeting our need adequately and making us have a sense of satisfaction or negatively by exposing us to unpleasant conditions thereby leading us to attempt a change. An organization cannot exist in isolation but will rather work with the overall environment. These environmental factors that either directly or indirectly influence an organization can be divided into two viz; internal environmental factors and the external environmental factors.

An organization internal environment refers to elements within the organization. Internally, an organization can be viewed as a resource conversion machine that takes input from the external environment and converts them into useful products, goods and services and make them available to customers as outputs. Those that makes up the internal environment includes; current employees, management, trade unions and shareholders. The external environment on the other hand consist of all the outside institution and forces that have an actual or potential interest or impact on the organization's ability to achieve its objectives. They include; competitive environment, technology environment, political environment and the legal environment.

The rate of turnover of employees has various effect on the organization and the society at large (Mobley 1982). The effects could either be positive or negative. Hence, a greater understanding of the process of labour turnover can increase the degree of which organization and employees within organization can influence this effect (Chory and Westerman, 2007). Turnover "as an individual's motivated choice behavior has widely been a studied outcome variable in industrial and organizational psychology literature for almost fifty years now. Although not all types of turnovers are negative, voluntary turnover that is dysfunctional and unavoidable can be very costly for any organization when considering the amount of investment an organization made in the recruitment, selection, classification and training of personnel.

Turnover intention have been said to indicate the relation between job related attitudes. Identifying factors that therefore contribute to dysfunctional turnover is important in order to take appropriate preventive actions. Generally turn-over is the term used to describe the departure of employee from an organization. It is a problem that many managers and leaders have to contend with in ensuring the survival of an organization. Most theorist that explain turn-over intention maintain that employees leave their jobs when their needs are not met and an alternative jobs becomes available which 
the employee beliefs will satisfy more of his need. This study therefore is an attempt to investigate the effect of organizational justice and organizational environment on employee's turnover intention.

\section{Hypothesis}

The following hypothesis shall be tested:

- There will be a significant effect of organizational justice and organizational environment on turnover intention.

- There will be a significant sex difference on organizational justice perception, organizational environment and turnover intention.

- There will be a significant difference in justice perception, organizational environment and turnover intention among the various categories of health workers.

\section{Methods}

\subsection{Participants}

Two hundred (200) research participants were used for the study, ninety eight male and one hundred and two females. Seventy five (75) participants were from the Ministry of Health, ninety five (95) from University Teaching Hospital and thirty (30) participants from the School of Nursing all within Ado Ekiti, Ekiti State, Nigeria. Participants were classified into four ranks which are Doctors (61), Lab-scientists (29), Nurses (85) and others (52).

\subsection{Measures}

Justice perception was measured using Organizational Justice Scale by Niehoff and Moorman (1993). It is an eighteen (18) item scale divided into three subscales which are distributive (5 items), procedure (5 items) and interactional (8items). Participants used a 6-point scale to report their perception of how fair certain aspects of their Job are. The scale Cronbarch alpha was. 95.

Environmental support was measured using the Basic Psychological Needs Scale (BPNS) by Deci and Ryan, (2000). The work domain form has 21 items, which participants rated on a 7-point scale. The scale reliability was. 88 .

Turnover intention was measured using Turnover Intention Scale developed by Fichman, Jenkins and Klesh (1979). It is a 3 item inventory. The Scale has an internal consistency coefficient alpha of. 78.

\subsection{Procedure}

The questionnaire was administered to each workers separately. This method was chosen in order to generate adequate responses from the workers. They were encouraged to read the instructions very carefully and ask questions on issues which seems unclear. After the administration, the filled questionnaires were immediately collected from the participants.

\section{Results}

The data collected was subjected to statistical analyses, the results of the analysis of data are present in the tables below which include a $2 \times 2$ analysis of variance, a t-test table and a correlation matrix.

Hypothesis one which state that there will be a significant effect of organizational justice and organizational environment on turn-over intention was tested using the $2 \times 2$ analysis of variance. The result is presented in the table below.

$<$ Table 1 about here $>$

The result shows a significant main effect of organizational justice on turnover intention. $F(1,199)=18.04 p<.01$, there is however no significant effect of organizational environment on turn-over intention and no interaction effect of Justice and environment on turnover intention. $\mathrm{F}(1,199)=.046 \mathrm{p} .>.05$.

Hypothesis two which state that there will be a significant sex differences in justice perception organizational environment and turn over intention was tested using the independent t-test the result is presented in the table below

\section{$<$ Table 2 about here $>$}

From the above table, the result reveals that there are no significant sex differences in organizational justice, organizational environment and turn-over intention

The third hypothesis which says there will be a significant difference in organizational justice perception, organizational environment and turnover intention among the various categories of health workers was tested using the one-way analysis of variance. The result is presented in the table below. 
$<$ Table 3 about here $>$

The above table shows that Nurses recorded the highest mean score on organizational justice perception compared to other categories of health workers $(\mathrm{F}(2,198)=3.51, \mathrm{P}>.05$. it can also be observed that Nurses has the highest mean score on turn-over intention as compared with other categories of health workers $(\mathrm{F}(2,198)=4.23, \mathrm{P}>.05$. There is no significant difference among the various categories of health workers on the perception of organizational environment ( $\mathrm{F}$ $(2,198)=1.48, \mathrm{P}<.05$.

\section{Discussion}

This Study examines the effect of organizational justice, organizational environment on turnover intention. The study shows that workers perception of justice is a great determinant of their decision to either stay or leave the organizations. This is in line with Folger and Konovosky (1989) researches that stated that justice perception will greatly influence turnover intention. The result from hypothesis I also states that there is no significant effect of environment on justice perception. This however negates other researches that see a great significant relationship between work environment and turnover intention.

Adams (1965) argued that social behavior is affected by beliefs that the allocation of rewards within a group should be equitable, that is, outcomes should be proportional to the contributions of group members. In other words, equity theory argues that people are satisfied when the ratios of their own inputs to outcomes (i.e., rewards) equal the ratios of inputs to outcomes in comparison to others. Perceived inequity through this comparison feels unpleasant, and motivates people to reduce those unpleasant feelings (Folger and Cropanzano, 1998)

In keeping with traditional equity theory research, contemporary studies have found that people tend to be less satisfied with outcomes they perceive to be unfair than those they perceive to be fair (Cropanzano and Greenberg, 1997). Such perceptions have been shown to result in poor performance (Cowherd and Levine, 1992; Pfeffer and Langton, 1993) and high rates of withdrawal behaviors, such as turnover and absenteeism (Hulin, 1991; Schwarzald, Koslowsky, and Shalit, 1992)

It can also be observed that there is no significant effect of organisational environment on turn-over intention. This finding is very surprising knowing that positive environment is critical to the satisfaction of the employee within the organisational. For example, by Trace, Scott and Michael (2005) they found out that work environment that exist in the work place affects the behaviour of employed workers. In their study it was discovered that both climate and culture had both direct and moderating effect on behaviour of employee. The findings of the research work also are also supported by Kristof (1996) and Netemeyer et al (1997), they found that a fit between the person and the environment is related to several job responses. Silverthorne (2004) investigating Taiwanese organisation indicates that positive environment will result in higher organisational commitment and lower turn-over intention.

The result also shows no significant sex difference in justice perception, organisational environment and turn-over intention. A review of related researches on sex and turn-over intention showed mixed result. Some studies e.g Miller and Wheeler (1992), Moncrief, Babakus, Cravens and Johnson (2000) suggest that females experiences higher turn-over rate above male while other studies such as Donnelly and Quirin (2006), Xu, Veloski, Hojat and Fields (1995) found no sex differences in turn-over intention.

Also while some studies e.g Miller (1998) have found sex difference in work environment perception other studies such as Kirschenbaun (1991) have found no significant sex difference in work organisation experience of both male and female. Duncan (1973) conducted a study where psychosocial and physical environments were compared with sex and it was found that there were no differences between men and women and that the type of activity involved in was more important than biological sex.

The result also reveals significant difference in justice perception and turn-over intention among the various health workers with a higher perceived injustice and turn-over intention among the nurses. This is in support of Bolton (2004) who discovered that nursing work has been deeply affected by government and management led initiatives to deliver quality patient service at lower cost and that the radical changes in the health care environment may result in mounting frustration among nurses. It is also a common knowledge in Nigeria that nurses feel deprived, cheated and marginalized by not been treated equally as the medical doctors. This might have accounted for higher perception of injustice and turn-over intention among nurses than other categories of heath workers. 


\section{References}

Adams, J. S. (1965). Inequity in social exchange. In L. Berkowitz (Ed.), Advances in experimental social psychology (Vol. 2), New York: Academic Press, 267-299

Bolton, S. C. (2004). A simple matter of control? NHS hospital nurses and new management. Journal of Management Studies, 4(2), 317-333. http://dx.doi.org/10.1111/j.1467-6486.2004.00434.x

Bonn, M. A., \& Forbringer, L. R. (1992). Reducing turnover in the hospitality industry: An overview of recruitment, selection and retention. International Journal of Hospitality Management, 11,(1), 47-63. http://dx.doi.org/10.1016/0278-4319(92)90035-T

Burney, L. L., Henle, C. A. \& Widener, S. K. (2008). "A path Model examining the relationship among strategic performance measurement system characteristics, organizational justice and extra-and-role performance". Accounting, Organizations and Society 34:305-321. http://dx.doi.org/10.1016/j.aos.2008.11.002

Cammann, C., Fichman, M., Jenkins, D. \& Klesh, J. (1979). The Michigan Organizational Assessment Questionnaire. Unpublished Manuscript, University of Michigan, Ann Arbor, Michigan.

Chory, R. M. \& Westerman, C. Y. K. (2007). "The role of justice in organizations: A meta-analysis". Organizational Behaviour and Human Decision Process 86:278-324.

Cowherd, D. M. \& Levine, D. I. (1992). Product quality and pay equity between lower level employees and top management: An investigation of distributive justice theory. Administrative Science Quarterly, 37, $302-32$. http://dx.doi.org/10.2307/2393226

Cropanzano, R. \& Greenberg, J. (1997). Progress in organizational justice: Tunneling through the maze. In C. L. Cooper., \& I. T. Robertson (Eds.), International Review of Industrial and Organizational Psychology, 12, 317-372. Chichester: John Wiley \& Sons

Donnelly, D. P. \& Quirin, J. J. (2006). An extension of Lee and Mitchell's unfolding model of voluntary turnover. Journal of Organizational Behavior, 27(1), 59. http://dx.doi.org/10.1002/job.367

Duncan, R. B. (1973). The Characteristics of organizational Environments and perceived Environmental uncertainty. The impact on organizational effectiveness. Human Relations Dorsey press, 273-291.

Dunnette \& L. M. Hough (Eds.), Handbook of Industrial and Organizational Psychology, 2, 445-506. Palo Alto, CA: Consulting Psychologists Press

Durbin, R. (1976). "Work in modern society" in R. Dudin (Ed) Handbook of work, organization and Society-Chicago, 111: Rand-Mc-Nelly, 282-287

Farris, G. (1969). “Organizational Factors and Individual performance: A longitudinal Study” Journal of Applied Psychology (Rev. Ed) pert Land Press, 87-92.

Folger, R. \& Cropanzano, R. (1998). Organizational Justice and Human Resources Management. Thousand Oaks, London: Sage Publications.

Folger, R., \& Konovsky, M. A. (1989). Effects of procedural and distributive justice on reactions to pay raise decisions. Academy of Management Journal, 32,(1), 115-130. http://dx.doi.org/10.2307/256422

Folger, R. \& Konovsky, M. A. (1989). "Effects of Procedural and distributive Justice on reactions to pay raise decisions", Academy of Management Journal, Vol 32 no2, PP115-130.

Garcia-Serrano, C. G. (1998). "Worker Turnover and Job reallocation: The role of fixed term contracts, oxford Economic papers, 50:709-725.

Gopanzano, R. E. \& Stein, J. H. (2009). “Organizational Justice and behavioural Ethics; promises; prospects”. Business Ethics Quarterly 19: 193-233.

Greeberg, J. (1996). The quest for Justice on the Job, Sage, Thousand Daks, CA. http://dx.doi.org/10.1037/0021-9010.72.1.55

Greenberg, J. (1987a). Reactions to procedural injustice in payment distributions: Do the means justify the ends? Journal of Applied Psychology, 72,(1), 55-61

Herzberg, F. (1967). "The motivation of work" in E.A. Fliesman (Ed) Studied in personnel and industrial Psychology. (Rev. Ed) Homeward 111: Dorsey press, 282-287 
Hogan, J. J. (1992). Turnover and what to do about it. Cornell Hotel and Restaurant Administration Quarterly, 33,(1), 40-45

Hulin, C. L. (1991). Adaptation, persistence, and commitment in organizations. In M. D.

Kirschenbaum, A. (1991). The corporate transfer: Origin and destination factors in the decision to change jobs. Journal of Vocational Behavior, 38, 101-123. http://dx.doi.org/10.1016/0001-8791(91)90021-D

Kristof, A. L. (1996). Person-organization fit: An integrative review of its conceptualizations, measurement, and implications. Personnel Psychology, 49(1), p.1-49. http://dx.doi.org/10.1111/j.1744-6570.1996.tb01790.x

Lawler, E. E (1992). The ultimate advantage of creating the high involvement organisation. San Francisco: Jossey- Bass.

McLaughlin, K. L (1991), “A theory of Quits and Layoffs with efficient turnover”, Journal of Political Economy, 99:1-29. http://dx.doi.org/10.1086/261738

Mobley, W. H. (1982). Some unanswered questions in turn-over and withdrawal research. Academy of Management Review, vol 7, no 1 111-116

Moncrief, W. C., Babakus, E., Cravens, D. W. \& Johnston, M. W. (2000). Examining Gender Differences in Field Sales Organizations. Journal of Business Research, 49(3), 245-257. http://dx.doi.org/10.1016/S0148-2963(99)00019-3

Netemeyer, R. G., Boles, J. S., McKee, D. O., \& McMurrian, R. (1997). An investigation into the antecedents of organizational citizenship behaviors in a personal selling context. Journal of Marketing, 61(30, pp.85-98

Niehoff, B. P., \& Moorman, R. H. (1993). Justice as a mediator of the relationship between methods of monitoring and organizational citizenship behavior, Academy of Management Journal, 36, 527-556. http://dx.doi.org/10.2307/256591

Pfeffer, J. \& Langton, N. (1993). The effects of wage dispersion on satisfaction, productivity, and working collaboratively: Evidence from college and university faculty. Administrative Science Quarterly, 38, 382-407. http://dx.doi.org/10.2307/2393373

Ryan, R. M. \& Deci, E. L. (2000). Self determination theory and the facilitation of intrinsic motivation, social development and well-being, America Psychologist 55, 68-78. http://dx.doi.org/10.1037/0003-066X.55.1.68

Schwarzwald, J., Koslowsky, M. \& Shalit, B. (1992). A field study of employees' attitudes and behaviors after promotion decisions. Journal of Applied Psychology, $77, \quad$ (4), $511-514$. http://dx.doi.org/10.1037/0021-9010.77.4.511

Sheppard, B. H., Lewicki, R. J. \& Minton, J. W. (1992). Organizational Justice: The Search for Fairness in the Workplace. New York, NY: Macmillan

Silverthorne, C. (2004). The impact of organizational culture and person-organization fit on organizational commitment and job satisfaction in Taiwan. Leadership and Organization Development Journal, 25(7/8), pp.592-599. http://dx.doi.org/10.1108/01437730410561477

Wofford, J. C. (1971). The motivational basis of Job satisfaction and Job performance. Personnel Psychology 24; 501-518. http://dx.doi.org/10.1111/j.1744-6570.1971.tb00373.x

Xu, G., Veloski, J. J., Hojat, M. \& Fields, S. K. (1995). Physicians' intention to stay in or leave primary care specialties and variables associated with such intention. Evaluation and the Health Professions, 18, 92-102. http://dx.doi.org/10.1177/016327879501800107

Table 1. A 2x2 ANOVA summary table showing the effect of organizational justice and organizational environment on turnover intention.

\begin{tabular}{|c|c|c|c|c|c|}
\hline Source & Ss & Df & Ms & F & P \\
\hline Organizational justice (A) & 49.70 & 1 & 49.70 & 18.04 & $<.01$ \\
\hline Organizational environment (B) & .68 & 1 & .68 & .24 & $>.05$ \\
\hline A X B & .13 & 1 & .13 & .046 & $>.05$ \\
\hline Error & 540.09 & 196 & 2.76 & & \\
\hline Total & 600.96 & 199 & & & \\
\hline
\end{tabular}


Table 2. A t-test showing sex differences in justice perception, organizational environment and turn-over intention

\begin{tabular}{|c|c|c|c|c|c|c|c|}
\hline Variable & Sex & $\mathrm{N}$ & $\mathrm{X}$ & $\mathrm{SD}$ & $\mathrm{Df}$ & $\mathrm{t}$ & $\mathrm{P}$ \\
\hline Organizational justice & Male & 98 & 35.71 & .472 & 198 & .184 & $<.05$ \\
\cline { 2 - 6 } & Female & 102 & 35.59 & .483 & & & \\
\hline Organizational environment & Male & 98 & 78.54 & 1.71 & 198 & 1.26 & $<.05$ \\
\cline { 2 - 6 } & Female & 102 & 76.86 & 1.67 & & & \\
\hline Turnover Intention & Male & 98 & 10.04 & 2.63 & 198 & 1.79 & $<.05$ \\
\cline { 2 - 5 } & Female & 102 & 10.48 & 1.87 & & & \\
\hline
\end{tabular}

Table 3. A one-way analysis of variance table showing the differences in organizational justice perception, organizational environment and turn- over intention among the various categories of health workers.

\begin{tabular}{|c|c|c|c|c|c|c|c|}
\hline Variable & Doctor & Nurse & Lab tech & Others & Df & $F$ & P \\
\hline Organizational justice & 30.20 & 37.5 & 35.6 & 35.20 & 198 & 3.51 & $>.05$ \\
\hline Organizational environment & 70.51 & 69.80 & 71.52 & 70.69 & 198 & 1.48 & $<.05$ \\
\hline Turn-over intention & 8.62 & 11.28 & 10.26 & 8.78 & 198 & 4.23 & $>.05$ \\
\hline
\end{tabular}

